Lepr Rev (1997) 68, 225-232

\title{
Study on the detection of leprosy reactions and the effect of prednisone on various nerves, Indonesia
}

\author{
E. H. M. BERNINK* \& J. E. J. VOSKENS \\ Provincial Department of Health, Section Communicable Diseases, \\ Jalan Undata 3, Palu/Sulteng, Indonesia
}

Accepted for publication 21 November 1996

Summary This paper presents a retrospective study on the detection of the treatment of leprosy reactions in a field situation, and the effect of prednisone on the various affected nerves.

Two patient cohorts were analysed.

The leprosy control programme in the testing area is not backed up by a specialized referral leprosy hospital, but patients are treated on an ambulatory basis at peripheral health centres by trained multipurpose health workers supervised by the health centre doctors. For operational purposes the guidelines and procedures for reaction management in the field were adjusted and partially simplified.

In both studies it appeared that the time of the occurrence of severe reactions was the same: $80 \%$ or more of the severe reactions occurred in the first year of treatment, the majority in the first few months after the start of the multidrug (MDT) treatment.

One third of all reaction patients suffered from a silent neuritis.

Well-instructed fieldworkers proved to be competent in detecting and treating leprosy reactions.

Treatment of severe reactions with prednisone in the field situation can preserve or considerably improve the functions of the affected nerves.

It is interesting that often the motor function of a nerve was found to be impaired without any loss in sensibility, which was tested using the ballpoint pen method.

\section{Introduction}

Central Sulawesi is one of the four provinces of Sulawesi Island in Indonesia. In 1985 treatment with MDT was gradually introduced and by 1992 all registered patients were on MDT.

In Indonesia the National Leprosy Control Programme is integrated with the general health services, provided at the health centres at subdistrict level. The health centre is the most peripheral health unit, serving a population of around $10,000-20,000$ and is staffed by a doctor and 10-20 paramedical staff.

\footnotetext{
* Correspondence: p/a Nyenheim 7109, 3704 BS Zeist, The Netherlands
} 
Since 1991 increasing attention has been given to patient care at the health centre level, and a range of activities were introduced, aiming at the prevention of permanent nerve impairment and disabilities: $:^{5-7,9,14,19}$ wound-care, patient education on self-care, early detection and treatment of complications like leprosy reactions and nerve function disorders, all these activities became a routine activity in the field; first as a pilot project, which was expanded step-by-step to the whole province. Fieldworkers received an intensive training course of 3 days on the aspects of prevention of disabilities (POD) after which they were allowed to treat reactions with prednisone under close supervision of the health centre doctors and supervisors.

This paper discussed two cohorts: the first contains 69 patients with severe reactions (125 nerves were affected), evaluated between March 1992 and March 1993. In this patient group the routine examination of the posterior tibial nerve was not included. The second cohort consisted of 85 patients with severe reactions (180 nerves were involved) and were assessed between March 1993 and March 1994. Fifty-one of the 85 patients had multiple nerve involvement.

Three people ( 2 district supervisors and 1 physiotherapist) were involved in doing the assessments.

Both groups of patients were treated with a similar minimum standard course of 10 weeks of prednisone.

For operational purposes leprosy reactions are only differentiated in mild and severe reactions: severe reactions include severe acute reversal reaction (RR) and/or a recent silent neuritis and/or a severe erythema nodosum leprosum (ENL).

The criteria for a severe reaction were:

a recent (less than 6 months) nerve function disorder (loss of sensation or muscle strength) in eyes, hands and/or feet;

nerve trunk tenderness;

ulceration of skin lesions; and

high fever and oedema of hands and feet.

All other reactions without nerve involvement were classified as mild reactions.

\section{STUDY QUESTIONS}

When is the majority of severe reactions detected?

Which nerves/nerve functions are affected most and what is the proportion of silent neuritis? What is the effect of a standard prednisone course (see Patients and methods) given under field conditions, on the various nerves, as regards nerve tenderness, muscle strength and sensibility or a combination of these $?^{10,17}$

Is a leprosy fieldworker capable of detecting severe reactions in time and of treating these reactions adequately?

\section{The following definitions were applied}

Nerve tenderness: of the ulnar, peroneal and tibial nerve. Tenderness was scored as 'present' or 'not present'.

Improvement was defined as going from 'present' to 'not present'.

The median and radial cutaneous nerves are not examined by fieldworkers (difficult to assess/less frequently affected). 
Muscle strength of the ulnar, median, peroneal nerve. Three gradings were used: a strong; weak; and paralysed. Strong was defined as 5 on the VMT score $(0-5 ; 0=$ paralysed, $5=$ normal strength); weak was defined as 3 ; paralysed was defined as 0 . Improvement was defined as an upgrading of the score.

Muscle strength ${ }^{3,11,12}$ of the facial nerve was assessed by the degree of lagophthalmos, but not measured, in millimetres. Lagophthalmos was scored as 'present' or 'not present'.

Sensibility of the ulnar, median and tibial nerves. Sensibility was tested by a light touch of the tip of a ballpoint pen. On the hands 10 points were examined: 5 for the ulnar part and 5 for the median part. On the feet: 11 points were tested. A difference of at least 2 points (within one nerve area) was considered to be a change in sensibility.

Silent neuritis was defined as recent sensory or motor nerve function impairment (i.e. developed within the last 6 months) without skin manifestation of RR, ENL or nerve tenderness.

Patients with nerve tenderness and/or nerve function loss of more than 6 months duration were excluded from being given prednisone, so they were not included in this study.

\section{Patients and methods}

Leprosy fieldworkers examined the nerve function of leprosy patients by using voluntary muscle testing (VMT), sensory testing (ST), and assessment of the disability/impairment status every 3 months. Quality control of the assessment was performed quarterly by supervisors. The status before and after prednisone treatment was compared in both studies by direct patient examination or data collection from individual patient records (disability/ nerve function assessment form).

The standard prednisone treatment started with a dose of $30 \mathrm{mg}$ for 2 weeks and tapered down with a minimum duration of 10 weeks. Every 2 weeks the patient was reassessed by the fieldworker and a decision was made on tapering down or extending the course or increasing the dose of prednisone. There was no maximum duration; the duration was fully determined by the condition of the individual patient and not by the type of leprosy or the type of reaction. ${ }^{13,15,16,18,20,21}$

\section{FIRST COHORT}

Out of 856 (130 PB, $726 \mathrm{MB})$ leprosy patients on the register 69 patients ( $8 \mathrm{~PB}, 61 \mathrm{MB})$ with severe reactions were observed, with 125 nerves involved.

Six patients suffered from an ENL reaction, 33 patients from an acute RR reaction, 3 patients from a combined RR and ENL reaction, and 27 from a recent silent neuritis. Thirtyseven out of 69 patients had a multiple nerve involvement.

Differentiation on the degree of tenderness, strength, sensibility or a combination of these after the treatment with prednisone was not recorded as such.

\section{SECOND COHORT}

Out of 751 (165 PB, $586 \mathrm{MB}$ ) leprosy patients on the register 85 patients (3 $\mathrm{PB}, 82 \mathrm{MB}$ ) with a severe reaction were observed, with 180 nerves involved.

Eleven patients were suffering from an ENL reaction, 2 patients from a combined RR/ENL 


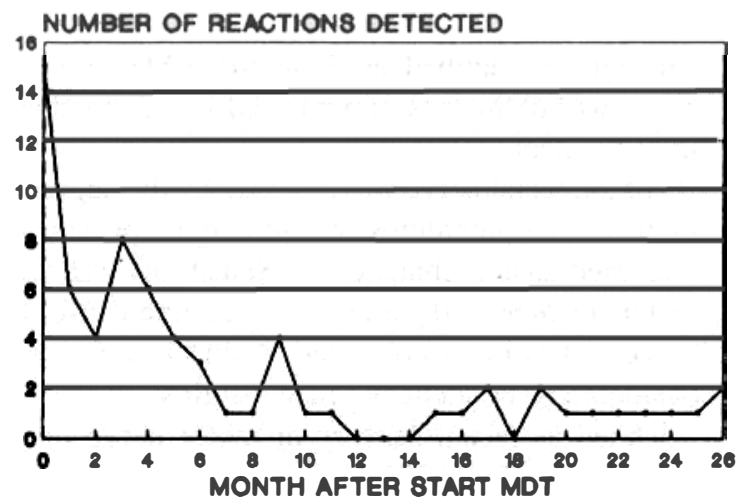

8tudy 1 (69 patlento)

Figure 1

reaction, 44 from an acute RR, 28 from a silent neuritis. Fifty-one out of the 85 patients had multiple nerve involvement.

Nerve tenderness of the posterior tibial nerve was only routinely examined in the 2 nd study.

In both studies there was no control group, as we regarded it as unethical to exclude patients from prednisone treatment.

\section{Results}

THE TIME OF DETECTION OF SEVERE REACTIONS

The first cohort (see Figure 1) showed that $80 \%$ of the reactions (55 out of 69 patients) were discovered within the first 12 months of MDT treatment. Fifteen out of 69 patients $(21.7 \%)$ were detected with a severe reaction at the start of the MDT treatment.

Study of the second cohort (see Figure 2) revealed that $82.5 \%$ of the reactions (70 out of

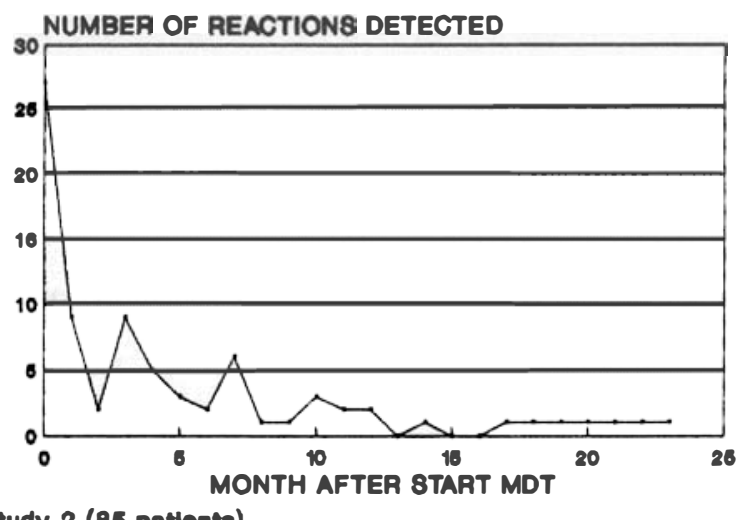

8tudy 2 (86 patienta)

Figure 2 
Table 1. Nerve involvement

\begin{tabular}{lrrrrr}
\hline & \multicolumn{2}{c}{ Cohort 1 } & & \multicolumn{2}{c}{ Cohort 2 } \\
\cline { 2 - 3 } \cline { 5 - 6 } & \multicolumn{2}{c}{$\%$} & & & $\%$ \\
\hline Facial & 3 & $(2.5)$ & & 9 & $(5)$ \\
Median & 3 & $(2.5)$ & & 9 & $(5)$ \\
Common peroneal & 30 & $(24)$ & & 43 & $(24)$ \\
Tibial posterior & 29 & $(23)$ & & 55 & $(30 \cdot 5)$ \\
Ulnar & 60 & $(48)$ & & 64 & $(35 \cdot 5)$ \\
& 125 & $(100 \%)$ & & 180 & $(100 \%)$ \\
& & & & & \\
\hline
\end{tabular}

Cohort 1 included 69 patients (8 PB, $61 \mathrm{MB})$.

Cohort 2 included 85 patients (3 PB, $82 \mathrm{MB}$ ).

85 patients) were discovered within the first 12 months of the treatment; $32 \%$ (27 out of 85 ) had a severe reaction at the start of treatment.

\section{NERVE INVOLVEMENT}

Table 1 shows the nerve involvement of the patients, included in both cohorts. The ulnar nerve is affected most frequently, the facial and median nerve the least.

In cohort 1 tenderness of the posterior tibial nerve was not included, which explains the lower incidence of tibial involvement in this study.

EFFECT OF PREDNISONE

In Table 2 the effect of prednisone on the affected nerves is given. Most nerves (75\%-80\%) improve either partially or totally.

Table 2. The effect of prednisone on the affected nerves

\begin{tabular}{|c|c|c|c|}
\hline & Improvement & Same & Worse \\
\hline \multicolumn{4}{|l|}{ Cohort 1: } \\
\hline Facial & 2 & 0 & 1 \\
\hline Median & 3 & 0 & 0 \\
\hline C. peroneal & 20 & 6 & 4 \\
\hline Tibial post. & 19 & 7 & 3 \\
\hline \multirow[t]{2}{*}{ Ulnar } & 50 & 7 & 3 \\
\hline & $94(75 \%)$ & $20(16 \%)$ & $11(9 \%)$ \\
\hline \multicolumn{4}{|l|}{ Cohort 2: } \\
\hline Facial & 6 & 3 & 0 \\
\hline Median & 7 & 2 & 0 \\
\hline C. peroneal & $36 \cdot 5 *$ & $6 \cdot 5^{*}$ & 0 \\
\hline Tibial post. & 41 & 10 & 4 \\
\hline \multirow[t]{2}{*}{ Ulnar } & 54 & 10 & 0 \\
\hline & $144 \cdot 5(80 \%)$ & $31 \cdot 5(17 \cdot 5 \%)$ & $4(2 \%)$ \\
\hline
\end{tabular}

$* 0 \cdot 5$, partial improvement to one affected nerve. 
Table 3. Nerve function involvement in the second cohort, before and after treatment with prednisone

\begin{tabular}{|c|c|c|c|c|c|c|c|}
\hline $\begin{array}{l}\text { Pattern of nerve } \\
\text { involvement } \\
\text { 'before'/'after' } \\
\text { prednisone }\end{array}$ & Tender & $\begin{array}{c}\text { Tender } \\
+ \\
\text { weak }\end{array}$ & $\begin{array}{c}\text { Tender } \\
+ \\
\text { anaesthetic }\end{array}$ & $\begin{array}{c}\text { Tender } \\
+ \\
\text { weak } \\
+ \text { anaesthetic }\end{array}$ & Weak & Anaesthetic & $\begin{array}{c}\text { Weak } \\
+ \\
\text { anaesthetic }\end{array}$ \\
\hline 'change' & $\mathrm{I} / \mathrm{S} / \mathrm{W}$ & $\mathrm{I} / \mathrm{S} / \mathrm{W}$ & $\mathrm{I} / \mathrm{S} / \mathrm{W}$ & $\mathrm{I} / \mathrm{S} / \mathrm{W}$ & $\mathrm{I} / \mathrm{S} / \mathrm{W}$ & $\mathrm{I} / \mathrm{S} / \mathrm{W}$ & $\mathrm{I} / \mathrm{S} / \mathrm{W}$ \\
\hline Facial & & & & & $6 / 3 / 0$ & & \\
\hline Median & & & & & $4 / 1 / 0$ & $2 / 1 / 0$ & $1 / 0 / 0$ \\
\hline Peroneal & $27 / 0 / 0$ & $4,5 / 2,5 / 0$ & & & $5 / 4 / 0$ & & \\
\hline Tibial $\mathrm{P}$ & $13 / 1 / 0$ & & $3 / 3 / 0$ & & & $25 / 6 / 4$ & \\
\hline \multirow[t]{2}{*}{ Ulnar } & $28 / 2 / 0$ & $7 / 2 / 0$ & $5 / 0 / 0$ & $3 / 2 / 0$ & $4 / 2 / 0$ & $1 / 1 / 0$ & $6 / 1 / 0$ \\
\hline & $68 / 3 / 0$ & $11,5 / 4,5 / 0$ & $8 / 3 / 0$ & $3 / 2 / 0$ & $19 / 10 / 0$ & $28 / 8 / 4$ & $7 / 1 / 0$ \\
\hline
\end{tabular}

'Weak' should be read as 'weak/paralysed'.

I, improved; S, same; W, worse.

The pattern of nerve disorder before treatment with prednisone is compared with the nerve disorder after treatment with prednisone.

In a few nerves we have found an improvement in tenderness while the degree of weakness/paralysis remained the same. This was recorded as ' $0 \cdot 5$ '.

Several patients showed a partial improvement against a partial nonimprovement within one affected nerve (see also Table 3). Tenderness was often improved, while the weakness and/or sensibility loss remained the same.

Only 15 patients received a prednisone course with a duration longer than 10 weeks, which led to a total nerve improvement in only 8 cases. However, we cannot draw any conclusions on the standard minimal duration of the prednisone treatment because this study does not compare various regimens.

Table 3 explains the pattern of nerve function involvement in the second cohort, before and after treatment with prednisone.

Table 4 shows the percentage of silent neuritis (on the total of affected nerves) in the second cohort.

Table 4. Percentage of silent neuritis-second cohort

\begin{tabular}{lcr}
\hline Nerves & $\begin{array}{c}\text { Total number of } \\
\text { affected nerves }\end{array}$ & Silent neuritis \\
\hline Facial & 9 & $9(100 \%)$ \\
Median & 9 & $9(100 \%)$ \\
C. peroneal & 43 & $9(21 \%)$ \\
Tibial P. & 55 & $35(64 \%)$ \\
Ulnar & 64 & $15(23 \cdot 5 \%)$ \\
Total & 180 & $77(42 \%)$ \\
\hline
\end{tabular}

Twenty-eight patients (out of $85,(33 \%)$ ) were suffering from silent neuritis (2 PB, $26 \mathrm{MB}$ patients).

All these patients had recent sensory or motor nerve function impairment without any other sign of reaction. 
In this study the total number of patients with a silent neuritis was 28 (2 PB, 26 MB); this is $33 \%$ of all patients, involving $42 \%$ of all nerves.

\section{Discussion/conclusion}

Of all diagnosed severe reactions $81 \cdot 25 \%$ were discovered within the first 12 months of MDT treatment. This is in line with other studies. Van Brakel ${ }^{1,8}$ found an occurrence of $95 \%$ (however he included also mild reactions in this study), Becx-Bleumink ${ }^{2}$ found an occurrence of $71 \%$.

Moreover, $27 \%$ of all patients appeared to suffer from a severe reaction at the time of the first patient contact. This number varies among the abovementioned authors between 59\% (Van Brakel) and 7.9\% (Becx-Bleumink).

Further data from both our studies show that most of the nerves (75-80\%) improved partially or completely with a standard prednisone course of 10 weeks minimum. The other authors used standard prednisone regimens of a much longer duration (12-20 weeks) with a higher starting dose of $40 \mathrm{mg}$. We should, however, note that most of the patients were examined not long after the full course of prednisone. There is still a possibility of recovery of the function of the nerve with time (like the tibial nerve which is known for its 'late' recovery) or the possibility of gradual deterioration of the nerve function, or the chance that a new reaction might occur.

Other studies are needed to define the optimal minimal duration of treatment and regimen of prednisone.

It is interesting that, contrary to the statement of Brandsma ${ }^{4}$ that 'changes in sensation are often an earlier sign of nerve involvement than changes in muscle strength', in our study of the affected ulnar and median nerves often (for median nerve: $55 \cdot 5 \%$; ulnar nerve: $9 \cdot 4 \%$ ) the motor function was found impaired without any loss in sensibility (see the second cohort). One of the reasons could be that the sensibility test using the ballpoint pen is less sensitive than other methods. Still it occurs that a patient has had a clear weakness of his/her hand for sometime, while there is no deterioration of the sensibility of the hand.

The relatively high percentage of 'silent neuritis' (33\%) proves that follow-up of the leprosy patient without a regular and proper VMT/ST examination will undoubtedly lead to impairments and disabilities in many patients.

This study also indicated that well-instructed leprosy fieldworkers are capable of detecting severe reactions in good time and are competent to treat these complications adequately in the field. ${ }^{22}$

Further studies wil be done with the same group of patients to detect 'late' recovery or deterioration of nerves, and with a new group of patients to verify the occurrence of a solitary muscle weakness of ulnar and median nerves, without sensory loss.

\section{Acknowledgments}

We would like to thank Dr Herman Wibowo, project director, and his leprosy field staff, who were so cooperative during all the years we worked in Central Sulawesi.

We are grateful to the Netherlands Relief Association, which enabled us to work on this study. 
Our thanks are also due to Dr Marijke Becx-Bleumink for her very helpful comments on the manuscript.

\section{References}

1 Van Brakel WH, Khawas IB, Lucas SB. Reactions in leprosy: an epidemiological study of 386 patients in West Nepal. Lepr Rev, 1994; 65.

2 Becx-Bleumink M, Berhe D. Occurrence of Reactions, their diagnosis and management in leprosy patients with multidrug therapy. Int J Lepr, 1992; 60, 00.

3 Brandsma JW. Intrinsic minus hand: (patho)kinesiology, rehabilitation and reconstruction. Doctorate theses. Published by: de Brandaen, Amersfoort, 1993.

4 Brandsma JW. Terminology in leprosy rehabilitation and guidelines for nerve function assessment. Trop Geograph Med, 1994; Vol 46: No 2, 00.

5 ILEP. Prevention of Disability. Guidelines for Leprosy Control Programes, March 1993.

${ }^{6}$ Watson JM. Preventing disability in leprosy patients. TLMI, 1986.

7 Srinivasam H. Prevention of disabilities in patients with leprosy. WHO. 1993.

${ }^{8}$ Van Brakel WH. Peripheral neuropathy in leprosy. The continuing Challenge. Doctorate thesis. The Hague, 1984.

9 Watson JM. Essential action to minimise disability in leprosy patients. The Leprosy Mission International. 1988.

10 Naafs B, Dagne T. Sensory testing: a sensitive method in the follow-up of nerve involvement. Int J Lepr, 1977; 45: 364-8.

11 Touw-Langendijk EMJ, Brandsma JW, Andersen JG. Treatment of ulnar and median nerve function loss in borderline leprosy. Lepr Rev, 1984; 55: 41-6.

12 Brandsma JW, Schreuders T, Birke J, Piefer A, Oostendorp R. Reliability of manual muscle strength testing in the evaluation of peripheral nerve dysfunction in leprosy patients. Paper presented at the 14th International Leprosy Congress, Florida, 1994.

13 Naafs B, Wheate HW. The time interval between the start of anti-leprosy treatment and the development of reactions in borderline patients. Lepr Rev, 1978; 49: 153-157.

14 Summers A. Leprosy for field staff. TLMI, 1993.

15 Rose P, Waters MFR. Reversal Reactions in leprosy and their management. Lepr Rev, 1991; 62: 113-121.

16 Imkamp FMJH. Standardized schemes for steroid treatment in ENL and reversal reactions. Int J Lepr, $1985 ; 53$. 313-317.

17 Pearson JMH. The evaluation of nerve damage in leprosy. Lepr Rev, 1982; 53: 119-130.

18 Kiran KU, Hogeweg M, Suneetha S. Treatment of recent facial nerve damage with lagophthalmos, using a semistandardized steroid regimen. Lepr Rev, 1991; 62: 150-154.

19 World Health Organization. Report of the consultation on disability prevention and rehabilitation in leprosy, Geneva, 1987. WHO/CDS/LEP/87.3.

20 Pearson JMH. The use of corticosteroids in leprosy. Lepr Rev, 1981; 52: 293-298.

21 De Soldenhoff R. Protocol for the Management of Reactions in the Field in Bauchi State, Nigeria. Unpublished.

22 A guide to eliminating leprosy as a public health problem (WHO 1995). 